\title{
La perspectiva biográfica en la investigación educativa. Una mirada a sus antecedentes, tendencias y posibilidades
}

\author{
The Biographical Approach in Educational Research. A Look at their Background, \\ Trends, and Opportunities \\ A perspectiva biográfica na pesquisa educacativa: um olhar sobre seus antecedentes, \\ tendências e possibilidades
}

\author{
Andrés Argüello P. \\ Departamento de Humanidades, Centro de Estudios en Educación, Universidad Santo Tomás - Bucaramanga, \\ Colombia. Telf.: (57) (7) 6800801 ext. 1293. Correo electrónico mouneriano@yahoo.es
}

\begin{abstract}
RESUMEN
La consideración del enfoque biográfico en la investigación social y, particularmente, en la investigación educativa se percibe como una apuesta epistemológica joven. Si bien se puede hablar de un sentido tradicional de las biografías que se remonta a la Antigüedad o el Medioevo, como se aprecia, por ejemplo, en las Vidas Paralelas de Plutarco o en los relatos hagiográficos, será el giro epistemológico de la nueva modernidad el que favorezca la extensión del género -hasta entonces histórico y literario- al territorio de las ciencias sociales y de la educación. El presente artículo se asoma, sin intenciones prescriptivas, a este proceso de surgimiento marcado por los grandes hitos de las teorías contemporáneas de las ciencias y sus inevitables impactos en la redefinición del estatuto científico de las realidades sociales y culturales, de donde la pedagogía ha recogido una inusitada diversificación de la biografía a través de métodos, aplicaciones y conocimientos.
\end{abstract}

Palabras clave: investigación biográfica, pedagogía, experiencia vital, historia social.

\begin{abstract}
The consideration of the biographical approach in social research and, particularly, in educational research is perceived as a young epistemological commitment. Although one can speak of a traditional sense of biographies that dates back to antiquity or the middle ages, as can be seen, for example, in Plutarch's Parallel Lives or hagiographic accounts, it will be the epistemological turn of the new modernity that favors the extension of the genre -until then, historical and literary- to the territory of social sciences and education. This article looks without prescriptive intentions, at this process of emergence marked by major milestones of contemporary theories of science and their inevitable impacts on the redefinition of the scientific status of the social and cultural realities, from where pedagogy has picked up an unusual diversification of the biography through methods, applications, and knowledge.
\end{abstract}

Key words: biographical research, pedagogy, life experience, social history.

\section{RESUMO}

A consideração do enfoque biográfico na investigação social e, em particular, na investigação educativa, é percebida como uma aposta epistemológica jovem. Se bem que se possa falar de um sentido tradicional das biografias que se remontam à Antiguidade ou à Idade Medieval, como se vê, por exemplo, em Vidas Paralelas, de Plutarco, ou em relatos hagiográficos, elas serão o giro epistemológico da nova modernidade, o que favorece a extensão do gênero - até então, histórico e literário - no campo das ciências sociais e da educação. O artigo mostra, sem intenções prescritivas, o processo de este surgimento caracterizado por grandes marcos históricos das teorias contemporâneas das ciências e seus inevitáveis impactos na redefinição do estatuto científico das realidades sociais e culturais, de onde a pedagogia tem recolhido uma inusitada diversificação da biografia, por meio de novos métodos, aplicações e conhecimentos.

Palavras chave: pesquisa biográfica, pedagogia, experiência vital, história social. 


\section{INTRODUCCIÓN}

Dicho de modo general y, por consiguiente, con el riesgo de enunciarlo con simplicidad, un estudio biográfico es la construcción direccionada, analítica y sistemática, de la historia de vida de una persona o de un colectivo, usando diversos tipos de documentos, según el caso, en el marco de un propósito específico de construcción de conocimiento, referido normalmente, a variadas aplicaciones de las ciencias sociales. La densidad de esta definición nos permite inferir que la llamada "perspectiva biográfica" no implica simplemente un sistema de técnicas sino, ante todo, un territorio epistemológico con sus consecuentes plataformas de interpretación, dispositivos de operación, pautas de sistematización y modos de análisis.

Para intentar desarrollar este principio, el artículo se estructura en torno a dos grandes momentos argumentativos. En primer lugar, se ofrece una mirada global del enfoque desde el punto de vista de su eclosión en las investigaciones sociales que, para efectos de este trabajo, comprende los estudios sobre la educación. En el segundo momento, se presentan las grandes tendencias aplicativas que, incluyendo el marco de la pedagogía, han ido dando madurez y diversidad a los usos biográficos contemporáneos. Por último, en el apartado conclusivo, se destacan algunos desafíos derivados de la aparición de la biografía en las investigaciones educativas.

\section{INVESTIGAR LA EXISTENCIA HUMANA DESDE LA PERSPECTIVA DE LOS SUJETOS: APUESTAS DE LA PERSPECTIVA BIOGRÁFICA (VER ARGÜELLO 2012)}

Con el ánimo de ofrecer un panorama de la epistemología biográfica, se debe favorecer, al menos brevemente, una revisión de los vectores originantes del enfoque para situar el horizonte conceptual desde donde éste es referenciado. Al respecto, hay que decir que el progresivo posicionamiento de la biografía en la investigación social tiene un antecedente remoto en la sociología interpretativa moderna asociada con las meditaciones de Dilthey sobre el estatuto de las llamadas "ciencias del espíritu" que impacta en algunos exponentes de la sociología proclives al paradigma de la comprensión (verstehen) y su método (Denzin, 1989: 13).

Sin pretender un desarrollo histórico exhaustivo de la conformación del enfoque, sino como pauta para ubicar el recurso biográfico dentro de la investigación social, se deben mencionar al menos tres hitos de particular incidencia, a saber: las influencias de la Escuela de Chicago y en ella de la escuela polaca como sociología emergente; el llamado "giro de la (nueva) Modernidad"; y, la readecuación de los estudios históricos dentro del movimiento postestructuralista.

Un primer punto a destacar, entonces, son los usos renovados de la oralidad que incorporó la sociología, de manera especial, a partir de la década de los veinte, del siglo pasado, dentro de la llamada Escuela de Chicago. Cabe mencionar, por el arrollador impacto de sus contribuciones en la manera de interconectar "la vida" -como entidad de conocimiento- con su realidad socio-cultural mediata e inmediata y con el contexto histórico, el trabajo The Polish Peasant in Europe and America (1918-1920), de William Thomas y Florian Znaniecki, quienes se convierten en precursores de una larga tradición de investigaciones sociales que dan la palabra a los sujetos insertos en dinámicas sociales 
complejas de marginación y exclusión, frente a un paradigma que evitaba las formas cambiantes del relato y los marcos inductivistas de comprensión histórica.

A partir de "El campesino polaco" se evidencia, además, la relevancia que jugó en este proceso de investigación la actividad intelectual de Polonia como explica la profesora Kaja Kaźmierska en un texto inédito sobre la emergencia biográfica en el pensamiento social:

Florian Znaniecki es principalmente conocido como el coautor de "El campesino polaco en Europa y América" -un estudio clásico de la Escuela sociológica de Chicago-, el cual es considerado como el comienzo del enfoque biográfico en sociología. En el contexto polaco, Znaniecki no es visto únicamente como alguien que ha dejado huella en el mundo de la sociología en general, sino que también es identificado como intelectual que estableció la sociología académica en el renacimiento de Polonia. En efecto, después de 1918, la sociología polaca configuró su propio estilo individual reconocido en el ambiente académico internacional. Así, en el libro de Coser sobre los maestros del pensamiento social, se destacan tres escuelas: la Escuela de Durkheim, la Escuela de Chicago y la Escuela Polaca, establecida por Florian Znaniecki. Él crea escuela con estudiantes que desarrollan y prolongan su obra, como ocurre en los trabajos de Jan Szczepański and Józef Chałasiński, co-fundadores del Instituto de Sociología de la Universidad de Łódź.

No en vano éste es un movimiento paradigmático que sobrevive los duros tiempos que afrontaron los estudios cualitativos, pues, mientras el neo-positivismo y los enfoques cientificistas dominaron la escena internacional de los estudios en ciencias humanas durante algunas décadas del siglo XX, el enfoque biográfico fue cultivado y desarrollado en el país del Este. Por eso en algunos manuales se habla del enfoque como el "método polaco".

Desde los aportes de este hito es interesante resaltar, al menos, dos elementos que prevalecerán en posteriores formalizaciones de la biografía investigativa. Por una parte, la diversificación de los materiales de análisis junto a la comprensión de la experiencia vital como campo de conocimiento científico. Znaniecki utilizó gran variedad de recursos de tipo biográfico, que el análisis posterior de K. Plummer (1989) llamará "documentos de vida": cartas personales, reportes de vida escritos y relatos biográficos sobre tópicos específicos de familia, sociedad o cultura. Incluso los mecanismos de recolección llegaron a ser convocados por anuncios públicos patrocinados por distintas organizaciones que premiaban y difundían los mejores documentos.

Además, el acto de animar a la gente a escribir y/o contar sus historias significó, en ese ambiente fragmentado de la posguerra, el cultivo de diversos tipos de memorias fundamentales en las tareas de reconstrucción del sujeto individual y colectivo. Al identificar los objetos de estudio al ritmo de los acontecimientos, de los procesos de transformación, de ese fluir de cotidianidades del que han hablado los enfoques de la "historia-proceso", se instaura la íntima vinculación individuo-estructura-historia planteada por C.W. Mills como uno de los mandatos epistemológicos de la investigación biográfica.

Ahora bien, el "giro de la Modernidad", que es ante todo un desplazamiento de cosmovisiones, está rodeado de una doble coyuntura histórica que sostiene las sociologías emergentes. Por una parte, el crecimiento exponencial de inmigrantes a las Américas desde la segunda mitad del siglo XIX y la ya mencionada etapa inmediata de la posguerra, que marcará la pauta para variadas formas de exilio en el curso del siglo XX. De otro lado, los empeños de conservación de los pueblos originarios y, en general, de los sectores sociales propensos a la extinción debidos a factores naturales o inducidos en los marcos de consolidación de los Estados Nacionales. En otras palabras, la biografía concebida 
en sus orígenes como investigación social tuvo una inmensa cuota de subsidiariedad con la producción e interpretación de la historia política, social y cultural de los pueblos.

Desde estos ambientes originantes, el método biográfico ha tenido diversos desarrollos, etapas de silencio y momentos de luminosidad, hasta un renovado interés en los últimos años tras la crisis a la que fue sometido, además, por la preponderancia estructuralista en las ciencias donde cierta tendencia de abuso del determinismo dominó también a las ciencias sociales atrapadas en la rigidez de "las estructuras". Sin embargo, al finalizar la década de los 80, Denzin afirmaba: "Hemos visto un resurgir del interés en enfoques interpretativos para el estudio de la cultura, la biografía y la vida del grupo humano" (Denzin, 1989: 9).

No debe olvidarse que la consolidación contemporánea de la perspectiva biográfica viene asociada a la crítica hacia el concepto moderno de sujeto basada en la transposición del estereotipo cartesiano a favor de un sujeto encarnado, contingente y situado (Birulés, 1996: 229).

Porque las realidades de la historia, incluyendo el devenir del sujeto, no se entienden ya desde la plataforma del mundo unificado típico de la razón moderna, ni desde el tiempo único y sus continuidades, el momento actual parece privilegiado para el despliegue de las particularidades y la atención de las diferencias (Birulés, 1996: 230). Los nuevos referentes de conceptualización están, entonces, vinculados a la fragmentación y contingencia de la subjetividad como se aprecia, por ejemplo, en las antropologías pos-colonialistas del siglo XXI. De manera que "buena parte de los interrogantes que nos deja por pensar el proceso de crítica radical de la razón y a los que parece urgirnos nuestra modernidad tardía son los que se articulan alrededor del complejo contenido de nociones que nos permiten decirnos, referirnos reflexivamente a nosotros mismos y a nuestro actuar" (Birulés, 1996: 232).

La deconstrucción del unívoco moderno en torno al "yo", a lo dado o "constituido como resultado de las supuestas 'continuidades' del sistema de acción individual" (Birulés, 1996: 232), da lugar a una importante inversión epistemológica donde la subjetividad inherente a la biografía llega a aportar conocimiento desde la construcción progresiva y continua del sujeto. En este orden de ideas se entiende que "el auge contemporáneo de la narrativa [y de los estudios biográficos, en general] tiene que ver con el creciente interés por el 'Yo' y la 'identidad' en muchas culturas" (Solinger et al., 2008: 8).

De alguna forma, ello explicaría cómo la biografía se va apreciando en una "inesperada etapa de éxito y prosperidad" a raíz, sobre todo, de los años ochenta del siglo XX (paradigma moderno de la biografía). Así, pues, si nos preguntamos a qué se debe el auge y el "reconocimiento científico" de la escritura de base experiencial y de los relatos autorreflexivos propios de la indagación biográfica tendríamos que mirar la consolidación de la biografía asociada al auge de "lo privado", de "lo subjetivo" y "lo particular" como parte de la racionalidad de las ciencias sociales (es decir, el giro de la nueva modernidad o "rebasamiento de la modernidad pura"). Es sin duda, una transición sustantiva. Pero, ¿dónde se cifra dicho potenciamiento del sujeto?

Como hemos planteado, en la revisión de paradigmas de conocimiento intervienen algunos factores que juegan un papel central en la rehabilitación epistemológica del sujeto, por ejemplo, los crecientes cuestionamientos a las explicaciones reduccionistas de las ciencias y la radicalización de las urgencias de la vida legadas por la filosofía 
existencial de la posguerra, así como por los renovados conflictos de la segunda mitad del siglo XX y sus dramas acentuados en el correr del tercer milenio.

Desde este marco de transiciones epistemológicas, el proceso de (re) creación del yo en la investigación biográfica se convierte en un elemento vertebral anudado a una particular manera de entender la temporalidad (tiempo - memoria) y el relato de sí (testimonionarración). En el valor semántico de la expresión "creación del Yo" - alusión de Paul John Eakin en su obra How Our Lives Become Stories: Making Selves, recuperado por Bruner y explicado por Denzin-, se halla contenido el núcleo de la preocupación biográfica: "El asunto central del método biográfico es la vida experienciada de una persona" (Denzin, 1989: 13). El énfasis se orientará entonces hacia la actividad de creación constante del sí-mismo (re-creación) que conlleva los procesos de apropiación del sujeto en su manera específica de construirse biográficamente como individuo en su complejidad de relaciones.

Sin embargo, la restauración de subjetividad y su extensión a los estudios biográficos en los giros de la racionalidad moderna no ha seguido un camino sin escollos. Desde las críticas del materialismo histórico, por citar un caso, se ha propiciado un amplio debate contra la concepción tradicional de biografía con base en una equívoca homologación del género con el individualismo posesivo.

Como es sabido, para el materialismo histórico el condicionante fundamental de la vida de la sociedad es la infraestructura económica, por lo que todo acento en el rol individual queda reducido a un segundo plano (Carreras, 2005: 127). Desde tal presupuesto se equipara biografía con exaltación a priori del individuo. Por eso, "el marxismo ortodoxo vio en la biografía muchas características que había denunciado como peligrosos desviacionismos de la conducta política. El subjetivismo, el voluntarismo, el individualismo (sobre todo bajo la forma de caudillismo), la tentación bonapartista del populismo, se contemplaron desde el marxismo-leninista más riguroso como residuos indeseables tanto de una mentalidad burguesa (la desviación derechista), como de un utopismo aventurista (la desviación izquierdista)" (Carreras, 2005: 127).

Las raíces de la crítica son, sin embargo, una voz de alerta. Al fin y al cabo, la biografía ha creído de modo tradicional en la acción de los individuos para la transformación histórica de su tiempo, en su capacidad de intervención en las condiciones de su época para un mejor estado de realizaciones (es lo que se ha llamado la interpretación whig de la historia que contribuyó a crear la atmósfera política liberal del siglo XIX).

Ante esto, los enfoques de la investigación histórica en el marco del movimiento postestructuralista han favorecido aquí un nuevo hito conceptual para el cultivo biográfico. La crítica al estructuralismo confronta la afirmación hiperbólica del yo y su correlato de pensamiento fragmentado. Este movimiento postestructuralista ofrece una readecuación del yo, según plantea el análisis de Corvez:

Lo impersonal es, por cierto, un factor estructurante del universo humano: la riqueza de la vida no proviene por entero del hombre que inventa sus manifestaciones [que crea sistemas, pues al fin las "estructuras" son creación humana]. Pero lo concreto y lo vivido, el sujeto y su libertad, la conciencia individual, son también realidades que no se pueden menospreciar ni anular (...). Lo cierto es que para pensar al hombre no sólo hay que querer hacerlo, sino querer que ese hombre sea reconocido en su totalidad y en sus características específicamente humanas (Corvez, 2000: 11).

Así, una comprensión de la biografía sometida aquí a revisión es aquella que la asume como un modo de escribir la historia capturada por el enfoque cuantitativo de las 
ciencias. Para Maurice Corvez, el estructuralismo contribuyó a un análisis científico de las realidades humanas inscrito en un referente de totalidad, de búsqueda de lo Uno, que controvierte la sucesión discontinua de culturas y dinámicas sociales:

Todos los estructuralistas buscan en la realidad humana aquellos aspectos de estabilidad, de inmutabilidad, que puedan brindar asidero a un conocimiento verdaderamente científico (...). Inserta en el corazón de lo real, pero más allá de lo inmediatamente visible, la estructura revela un aspecto oculto de las cosas (...). El análisis estructural, descuidando lo puramente accidental, intenta poner de manifiesto el código secreto que vincula las múltiples actividades del hombre: su organización social, su vida económica, sus creaciones artísticas, su lenguaje, y aun su actividad psíquica e intelectual. En todos estos ámbitos, ya sea que se exprese la estructura con la palabra sistema, categoría, esquema, concepto, etc., se trata siempre de puntos de vista fijos, de conjuntos cerrados, de factores permanentes, que el estructuralismo descubre en los encadenamientos controlables de la actividad humana. De este modo, la noción de totalidad sistemática aparece como uno de los resortes esenciales del análisis estructural, que le permite alcanzar verdadera objetividad y apuntar con rigor a la formulación exacta de leyes generales (Corvez, 2000: 8s.).

Particularmente los estudios históricos de cara al recurso biográfico, fueron influidos por estas tensiones que marcaron sus tendencias y posibilidades. En la Antigüiedad y en el Medioevo, en continuidad con el referente griego, se habló de la biografía desde el paradigma de la "vida ejemplar" (Hernández Sandoica) o de la "Historia magistra vitae" (Dosse). Aquí la conformación y divulgación de cierta historia de vida tenía carácter ejemplarizante y de lección moral. Pero, desde tal óptica, ¿quién se propone a la emulación? Ciertamente, aquel que en efecto puede continuar o reforzar los sustratos del establecimiento epocal, la visión dominante de política y sociedad que sólo persiste si hay un colectivo que la sostenga. Por eso la biografía, desde tal óptica, aparece como "un importante instrumento en la "creación cultural del yo" (Hernández Sandoica) donde las Vidas y experiencias son fuente de mímesis y de posibilidad.

No obstante, la concepción moralizante de la biografía no puede ser inmune a la crítica de la escuela historiográfica francesa de los Annales, donde Lucien Febvre ataca la "historia historizante" que precisamente asocia con las pretensiones de la biografía pues "su finalidad no era otra que reunir los hechos a partir de los documentos, coordinarlos entre sí y luego exponerlos" (Carreras, 2005: 127). De hecho, valga decir que un uso desprevenido de la indagación biográfica fácilmente podría caer en ese trámite descriptivo de la historia, en una exposición de sucesos al modo de las lógicas popperianas llamadas de "primer orden". En contraposición, la propuesta de Fernand Braudel con sus estructuras de lo cotidiano (que ante todo son estructuras invariables a través de largos periodos de tiempo) trastoca el interés por los episodios al considerar que éstos distraen el trabajo del investigador de la "auténtica realidad objeto de interés".

Para tal enfoque existe una tensión entre el tiempo breve y el tiempo de larga $\mathrm{du}$ ración de la Historia. El tiempo breve, propio de periodistas y biógrafos, no puede ser objeto de atención de la historia social por considerarse el "más caprichoso y engañoso". El análisis que realiza Carreras es provocador: "Este hecho ha tenido consecuencias lamentables cuando se ha contemplado el modelo francés como el ejemplo a imitar. No puede ignorarse que la historiografía francesa tenía una brillantísima tradición en la línea más positivista, más atenta a la verificación del hecho, que llevaba decenios frecuentando los archivos en una casi fetichista búsqueda de datos y, desde luego, declaradamente historizante" (Carreras, 2005: 128-129). 
No es en vano la afinidad entre Braudel y el estructuralismo, pues no se concibe que la historia se explique desde el individuo. En torno a esta tensión, Maurice Corvez plantea:

A causa de la rígida fijeza de su objeto, el punto de vista estructural se opone, en términos globales, a la consideración histórica. Se sitúa en forma deliberada al margen del tiempo. La historia vivida y concreta de los hombres pasa a segundo plano, cuando no se descalifica su existencia misma, por lo menos con relación al pensamiento filosófico. El sistema está primero y condiciona los sucesos: he ahí una proposición que todos los estructuralismos comparten. La historia individual o colectiva de los seres humanos no cuenta casi en una perspectiva puramente cientifica (...). La tendencia general consiste, pues, en reducir en lo posible la realidad del sujeto humano -del protagonista de la historia, justamente- y, en el caso extremo, en suprimirlo en forma lisa y llana. El pensamiento se vuelve impersonal, algo construido con independencia de todo sujeto capaz de expresarse y actuar con real autonomía (Corvez, 2000: 10).

Ahora bien, será la misma tradición de los Annales la que procure un "acercamiento postestructuralista" a la biografía a través de sus exponentes de la llamada "cuarta generación". George Duby, por ejemplo, al plantear su propuesta de la "historia de las mentalidades" acentúa la necesidad post-factual de la comprensión histórica que exige la caza de significaciones, mediaciones simbólicas, creaciones culturales, en suma:

Obligados, por supuesto, a menudo, a comprender qué queríamos conseguir con una determinada personalidad, nos esforzábamos por extraer de sus pensamientos lo singular. Dado que no aceptábamos separarla de su cuerpo, tampoco consentíamos que se aislase a ese individuo del cuerpo social al que pertenecía. Por mentalidades entendíamos el conjunto borroso de imágenes y de certezas no razonadas al cual se refieren todos los miembros de un mismo grupo (Duby, 1992: 102). ${ }^{1}$

De igual manera, François Dosse, con su planteamiento de la biografía como "historia intelectual", contribuye a precisar los vínculos entre individuo, contexto y obra en tanto sistema de interpretación. Así, volvemos a creer en la figura encarnada de un autor, sin poder obviar que las obras (literarias, intelectuales, culturales en suma) son resultado de la intervención de alguien -como bien apunta el escritor Antonio Muñoz Molina- "del trabajo de alguien, no emanaciones abstractas surgidas de ninguna parte y flotando como plankton anónimo en el laberinto o en la gran sopa verbal de otros textos, todos ellos engendrados por la ambición del poder o por las construcciones ideológicas de los géneros o los sexos o las identidades opresoras o liberadoras" (Castilla y Fietta, 2009: 9).

La producción intelectual no aparece, entonces, desmembrada de la conformación orgánica y de la presencia vital que se imprime en ella: "Importa mucho buscar los lazos entre la vida y la obra de alguien, averiguar el origen siempre azaroso y las circunstancias en que llegaron a existir esos libros que de otro modo parecerían surgidos de una especie de necesidad histórica" (Castilla y Fietta, 2009: 9).

Las réplicas de estos pilares halladas en otras cosmovisiones emergentes de las ciencias sociales, como la antropología simbólica (Geertz), la historia oral (Thompson) o las epistemologías poscoloniales (Morin y otros), ha trazado un nuevo paisaje para

$1 \quad$ El recuento de la historia de las mentalidades ilustra el marco interpretativo constituyente: "Marc Bloch, desde Les Rois thaumaturges hasta La sociedad feudal, invitaba a tener en cuenta la 'atmósfera mental'. Con más insistencia, Febvre invitaba a escribir la historia de las 'sensibilidades', la de los olores, los temores, el sistema de valores. Su Rabelais mostraba magníficamente que cada época elabora su propia visión del mundo, que las maneras de sentir y pensar varían con el tiempo, y que, por consiguiente, el historiador está obligado a defenderse en lo posible de las suyas bajo pena de no entender nada. Febvre nos proponía un nuevo objeto de estudio, las ‘mentalidades'. Ése era el término que empleaba. Nosotros lo retomamos” (Duby, 1992: 98). 
comprender el estado del debate de la investigación biográfica hoy. Cobran un renovado lugar recursos como relatos, autobiografías, memorias narradas o escritas, y otras implementaciones que invocan las estrategias de análisis e interpretación desde multiplicidad de "documentos personales", ofrecidos muchas veces como materiales históricos, ahora desde una postura interpretativa.

De igual forma, a propósito de una reconstrucción epistemológica amplia, para la situación concreta de América Latina, se hace particularmente patente la herencia de la perspectiva biográfica, a saber, las preocupaciones por la recuperación simbólica y práctica de los sectores socio-culturalmente vulnerables, y el retorno al sujeto como giro legítimo para comprender fenómenos abordados por la investigación social en sus variadas y complejas áreas de interés. Un componente de ese universo de cuestiones, formulaciones e iniciativas es la conexión entre biografía y estudios sobre la educación, de la cual se tratará en el siguiente apartado.

\section{CONSIDERACIONES PARA UN ESTADO DEL DEBATE SOBRE "LA CUESTIÓN BIOGRÁFICA"}

Reconstruir la vida de un individuo o una colectividad en algún ámbito de la experiencia humana para favorecer el desarrollo de un tema y la discusión en torno a problemas, a partir de materiales, documentos y contribuciones derivados de trayectorias de vida personal o institucional, son caracterizaciones que, desde una mirada general, configuran el horizonte de la investigación biográfica.

Desde ese horizonte, es posible establecer una relación de afinidad entre los avances más destacados en este campo y los desarrollos de la investigación educativa. Así, las grandes tendencias que se pueden identificar en el plano de los estudios biográficos son las mismas que pueden ser especificadas al hablar de ellos en el campo de la educación.

Para intentar un estado del debate lo más preciso posible, aunque breve según los alcances de esta presentación, se deben tener en cuenta algunas consideraciones. Hablar de biografía en el momento actual implica situarse en un cruce de caminos donde converge la literatura, como re-creación del Yo a través de la palabra; la historia, como identificación de vectores situacionales de producción de sujetos; y la investigación social como acto formal de análisis para la comprensión de fenómenos. Por eso, es menester precisar que el referente de la investigación desde la perspectiva biográfica que aquí aludimos, toma distancia de la idea posmoderna que alienta la satisfacción en torno al consumo voraz de historias. Dicho de otro modo, la referencia que incumbe a este breve estado del debate es la perspectiva biográfica asociada a los criterios del rigor y la epistemología propios de un ejercicio investigativo formal y no la proliferación de productos pseudo-biográficos fragmentados (Goodley et al., 2004). Por eso se prefieren aquí las alusiones a centros especializados y programas formales de investigación por encima del vasto ámbito informal de las llamas "biografías de consumo".

Como menciona R. Sautu, "la investigación biográfica consiste en el despliegue de sucesos de vida (cursos de vida) y experiencias (historias de vida) a lo largo del tiempo, articulados con el contexto inmediato y vinculados al curso o a historias de vida de otras personas con quienes han construido lazos sociales (familia, escuela, barrio y trabajo)" (Sautu, 2004: 22). El mismo sentido relacional que integra individuo, agencias colectivas y 
sociedad en general, es manifestado por Mallimaci y Giménez: "El investigador relaciona una vida individual/familiar con el contexto social, cultural, político, religioso y simbólico en el que transcurre, y analiza cómo ese mismo contexto influencia y es transformado por esa vida individual/familiar" (Mallimaci y Giménez, 2006: 178). Aparece, una vez más, la tríada biografía-estructura-historia que no sólo implica la disciplina de la fundamentación en formato, procedimiento y producto, sino los criterios de la racionalidad y la epistemología que son las bases requeridos para que un proyecto de interés común sea una apuesta científica.

De igual forma, el carácter extensivo, creciente y polifacético de los estudios biográficos determina el talante provisional de cualquier estado del conocimiento que pretenda formularse. ${ }^{2}$ No se ha pretendido, sabiendo la imposibilidad pragmática de tal empeño, dar cuenta de manera absoluta de todas las producciones del saber generadas en cada enfoque. El grupo de autores o tendencias que se esboza sólo intenta ilustrar un panorama suficiente pero necesariamente inacabado de las comunidades de pensamiento, redes, autores y creaciones más significativas dentro de las líneas de investigación que relacionan biografía y educación. La mención de algunos exponentes, proyectos y centros destacados no es taxativa y determinante. Es más una invitación para que los interesados profundicen en las referencias de su interés y continúen completando el trabajo.

\section{DIRECCIONES DEL ENFOQUE BIOGRÁFICO EN LA INVESTIGACIÓN EDUCATIVA}

Según se ha indicado, el eje interpretativo de los estudios biográficos es la construcción de la trayectoria vital de un sujeto individual o colectivo, a partir de documentos orales o escritos, para comprender la génesis, configuraciones y transiciones de experiencias y "políticas de vida" (cosmovisiones) que rigen el mundo cotidiano en sus distintas conformaciones (naturaleza de las costumbres, anatomía de pensamientos, genealogía de prácticas, etc.). ${ }^{3}$

Dentro de las delimitaciones y aplicaciones de este eje se pueden identificar, al menos, cuatro enfoques de especial importancia.

En primer lugar, la investigación biográfica en torno a un personaje (individual o colectivo) como análisis integrador que conlleva el uso de la biografía para la reconstrucción histórica de época y situación. Para citar un caso afín a los estudios culturales, se halla en México el Instituto de Investigaciones José María Luis Mora, que ha realizado publicaciones

2 Dos trabajos de especial relevancia deben ser considerados aquí, aunque no deben abordarse con pretensión definitiva. Por una parte, el estado del debate "La investigación biográfica y narrativa en Iberoamérica: campos de desarrollo y estado actual" publicado en 2006 por Antonio Bolívar y Jesús Domingo en el Forum: Qualitative Social Research, Vol. 7, No. 4, art. 12. De otro lado, el documento "Biographical Research in the $U K$ ”, de Brian Roberts, que desde el referente europeo brinda una visión global de las tendencias actuales más representativas de la iniciativa biográfica (Newsletter Research Comittee 38, International Sociological Association, junio 2012).

3 De ahí que la constitución de historias de vida, como expresión específica del método biográfico que vincula experiencia individual y realidad histórica, se estructure temáticamente en torno al objeto de estudio definido para cada investigación. De hecho, ante la densidad e inacabamiento que implican los estudios centrados en la existencia humana, una prioridad típica del método biográfico es depurar la pertinencia de la selección. 
de biografías de distintas personalidades centrándose en diversas temáticas relacionadas con la política, la economía, el género, la educación, la actividad cultural, entre otras. ${ }^{4}$

De modo semejante, pero con un enfoque más centrado en la consideración de hechos históricos, se halla el trabajo realizado por James W. Wilkie y Edna Monzón en torno a 17 líderes de la revolución mexicana en su etapa constructiva, que emprende la conformación de trayectorias con base en entrevistas que conectan la experiencia personal de los personajes con la historia política del país en el siglo XX. De igual forma, como análisis histórico de épocas o situaciones a partir del punto de vista de los actores fundamentales que vivieron los acontecimientos, se encuentran también los análisis del periodismo investigativo, los trabajos de campo, por ejemplo, de Mary Kay Vaughan, de la Universidad de Maryland, USA, y, en general, la línea de procedimientos biográficos en investigaciones sobre historia de la educación.

Esta primera tendencia recoge, pues, los estudios biográficos sobre maestros considerados de "especial representatividad", propulsores de patrones de cultura y de formación por la pertinencia de sus contribuciones, o por la calidad de los debates que suscitaron en un determinado marco de condiciones históricas. También entran aquí los trabajos sobre instituciones educativas en tanto genealogía de prácticas o como procesos fundacionales con sus rutas de evolución y desarrollo.

En suma, se pueden establecer tres grandes características para los trabajos de este tipo: a) son estudios que desarrollan una visión descriptiva de la biografía que da cuenta de la vida y obra de un personaje; b) son estudios que ofrecen un tratamiento de tipo biográfico sobre cuestiones temáticas específicas; por ejemplo, entender una época particular o un fenómeno socio-cultural determinado desde el punto de vista de quien lo ha vivido o de los roles asumidos en tales contextos; y c) son trabajos que entrañan la posibilidad de estudiar todo tipo de personaje: los criterios de selección están en el arbitrio del biógrafo y en la necesidad social.

En segundo lugar, la investigación biográfica como análisis temático a profundidad o biografía intelectual, puede concebirse como una particularización del primer enfoque que conduce el interés por las plataformas históricas hacia las producciones culturales $\mathrm{y}$, en particular, a las obras de conocimiento vinculadas al desarrollo de la pedagogía o a la exposición de teorías educativas de singular reconocimiento.

Mientras la utilización de enfoques biográficos desde vertientes sociales, como suele ocurrir con las historias de vida, tiende a referirse a muestras de poblaciones o grupos de estudio, la biografía intelectual se concentra en la vida y obra de un personaje. Se trata, entonces, de una variante de la biografía panorámica, donde prima la visión de totalidad aunque guiada por patrones de selección, que se realiza como estudio de caso único a partir de la representatividad de un individuo en algún escenario del mundo intelectual. La diferencia con otras formas de estudiar la existencia humana es contar

\footnotetext{
La línea dominante de estos trabajos es la exaltación de personajes, de proyección nacional o mundial, desde un punto de vista histórico (en algunos casos adopta la forma de ensayo histórico-biográfico o ensayo biográfico). Las biografías que aquí se encuentran podrían admitir una clasificación propedéutica: biografía del personaje prototípico mundial (Cristóbal Colón, por Luis Arranz; Che Guevara, por Alain Ammar; Wiston Churchill, por Sebastián Haffner; Calvino, por Bernard Cottret); biografía del personaje de la intelectualidad (Theodor W. Adorno, por Detlev Claussen; Marc Bloch, por Olivier Dumoulin ); y, biografía del caudillo mexicano (tiempos de revolución, Hidalgo, Juárez, Villa y otros personajes mexicanos del siglo XIX).
} 
con el requisito de la obra intelectual y las sinuosas relaciones entre la generación de ésta y la trayectoria de vida.

En el desarrollo de la investigación biográfico-intelectual, es preciso resaltar los aportes de la tradición francesa, que se ha centrado en la restauración de la intelectualidad particularmente del siglo XX. Aquí se puede apreciar con nitidez la pretensión fundamental de la biografía intelectual al enriquecer la creación de un sistema de pensamiento, desde la constitución existencial de un sujeto en medio de sus múltiples azares y determinaciones.

Dentro de la biografía intelectual se destaca fundamentalmente la construcción de trayectorias que acentúan la unidad entre vida y pensamiento del autor, aunque sin excluir sus opacidades allende las fases de evolución intelectual del personaje asumido como entramado esencial de ideas.

Así, por ejemplo, las biografías intelectuales de Paul Ricoeur (Los sentidos de una vida) y Michel de Certeau (El caminante herido), realizadas como sendos trabajos de investigación por François Dosse, tienen preferencia por el primer estilo, el interés por dar concreción a los conceptos en la trama de la existencia. ${ }^{5}$

Ahora bien, la biografía intelectual, dentro de una estrategia de investigación, sea referida a las ciencias sociales en general o a la educación en particular, reclama la concentración en autores de estudios definidos contra la dispersión de la totalización teniendo en cuenta que ninguna pesquisa biográfica puede dar cuenta plena de la vida de un individuo.

En tercer lugar, se hallan los estudios biográficos orientados a la comprensión de procesos psíquicos, sociales o culturales, donde tiene especial desarrollo la construcción de trayectorias profesionales y el énfasis de la función política de la educación. Por la multiplicidad de los desarrollos en esta vertiente, podría afirmarse que éste es uno de los pilares contemporáneos del binomio biografía-educación.

Desde distintas perspectivas de las ciencias sociales se identifican algunas influencias útiles para este apartado. Quizás el referente más sobresaliente por su extensión, densidad, sistematización y división temática, es la International Oral History Association (IOHA), que viene realizando bianualmente un encuentro internacional para poner en común las investigaciones en curso y consolidar las redes extendidas ya en los cinco continentes. De este modo, la IOHA ha contribuido a la definición científica de los estudios sobre

En esta tendencia puede entenderse también el trabajo de Annie Cohen-Solal, quien realizó "una imponente biografía de Sartre que cuestionaba, a lo largo de toda la trayectoria, la coherencia de la postura del intelectual comprometido con la Ciudad" (Dosse, 2007: 399). Es el sentido que compete a la biografía intelectual cuando trata la relación entre la actividad intelectual dominante del autor y sus compromisos políticos. Esta tensión se refleja, además, en la investigación de Víctor Farias, titulada "Heidegger y el nazismo", donde muestra el contraste entre el ilustre pensador de la filosofía contemporánea y sus cuestionadas simpatías con el nacionalsocialismo. Ocurre igual con "Mircea Eliade, el prisionero de la historia", donde Florin Turcanu expone la paradoja entre la militancia fascista del intelectual rumano y sus invaluables aportes para la renovación de una fenomenología de las religiones. Las tensiones entre la obra producida y la existencia vivida parecen ser, entonces, una preocupación de la tradición biográfica francesa contemporánea. A este propósito, un asunto a considerar es que la coherencia, si se quiere, moral, del autor no viene antecedida necesariamente por la palabra escrita, pues la producción intelectual, como todo escrito, está sometido a la ambigüedad de la representación; es acto segundo que, por ente, puede resultar falaz. De ahí que la experiencia vivida se convierta en el patrón primario de legitimación ética. En sentido estricto, no es que haya una ruptura de pensamiento frente a la obra sino una exótica unidad permanente de vida. La obra, desde esta mirada, sería una "ficción circunstancial". 
experiencias vitales mediante el perfeccionamiento de los diseños metodológicos basados en fuentes orales y una extensa oferta temática. ${ }^{6}$

En este punto, es preciso hacer mención del trabajo editado por R. Solinger, M. Fox y K. Irani, Contar historias para cambiar el mundo (Telling stories to change the world), el cual recoge 23 informes de investigación acerca de las maneras como activistas por la justicia social, artistas y líderes de diversos lugares del mundo, insisten en el poder que las historias tienen para generar esperanza y compromiso, dignidad personal y ciudadanía activa, al tiempo que afianza el orgullo de las identidades y la interdependencia de los vínculos humanos. De este modo, se refiere el uso de historias como una estrategia fundamental para generar reclamaciones de justicia social.

En el conjunto de tales investigaciones, grupos de personas crean narrativas que identifican obstáculos a la libertad, la salud, la seguridad, la dignidad y otras principales reclamaciones de la democracia moderna. En respuesta a esos obstáculos, los sujetos en sus grupos construyen relatos mediados por voces y visiones que implícita o explícitamente reclaman un mundo mejor. Aquí podrían establecerse posibles acercamientos entre la biografía y los enfoques críticos de la educación que insisten en la transformación de sistemas opresivos desde la "recuperación colectiva de la historia-desde-abajo", tales como la pedagogía comunitaria o las modalidades de educación popular.

Dando un paso más, debe señalarse, de manera especial, el uso de enfoques biográficos que hacen explícita la influencia de fenómenos de la vida socio-cultural en el ámbito educativo. Este plano comprende las investigaciones desde la sociología y, en general, las ciencias sociales, que utilizando la biografía han tenido impacto en cuestiones pedagógicas de diversa índole. Una expresión de esta corriente se aprecia en el Centro de Métodos en Ciencias Sociales, de la Universidad de Göttingen. Este organismo, dirigido por Gabriele Rosenthal, lleva a cabo estudios biográficos en torno a identidad étnica, programas juveniles en torno a la educación y diversos tópicos de análisis socio-cultural.

En línea similar se halla el Instituto de Sociología de la Universidad de Łódź (Polonia). Aquí se pueden mencionar los trabajos de Kaja Kaźmierska, cuya investigación está basada en análisis de entrevistas biográfico-narrativas y problemas sobre identidades y/o

$6 \quad$ Entre las líneas de investigación más destacadas de la IOHA se pueden mencionar las siguientes: memorias de violencia, guerra y totalitarismo; memorias de participación política; culturas emergentes; memorias de familia; migraciones; mundo del trabajo; género y memorias de identidad sexual; cuidado de la salud; ecología y amenazas medioambientales; religión y tradiciones orales; organización y administración de la historia oral; metodología, enseñanza y mass-media en la historia oral. A nivel latinoamericano la IOHA hace presencia de manera especial en los proyectos de la Asociación Mexicana y la Asociación Brasileña de Historia Oral, ésta última con una importante vinculación al ámbito de la pedagogía por el uso de historias de vida en la formación de maestros e historia de la educación. Dentro de la expresión epistémica y metodológica de la historia oral como estudio biográfico, se pueden resaltar los trabajos del "Center for Ageing and Biographical Studies" (CABS) de Open University. Junto a la Escuela de Salud y Bienestar Social (School of Health and Social Welfare), Joanna Bornat ha aportado una amplia tradición en proyectos de historia oral comunitaria para realizar investigaciones de oralidades y trayectorias de vida en gerontología o áreas afines con un sentido de conexión entre teoría, investigación, política y práctica. Puede notarse, también, que en el conjunto de investigaciones de estudiantes de posgrado de la Facultad de Salud, se ha consolidado la concepción de los estudios biográficos como método de investigación cualitativa. A nivel latinoamericano la IOHA hace presencia de manera especial en los proyectos de la Asociación Mexicana y la Asociación Brasileña de Historia Oral, ésta última con una importante vinculación al ámbito de la pedagogía por el uso de historias de vida en la formación de maestros e historia de la educación. 
memoria colectiva desde experiencias biográficas de la Europa del Este. ${ }^{7}$ Así mismo, la International Sociological Association (ISA) a través de su comité de investigación sobre biografía y sociedad (Research Comitee 38) analiza las relaciones entre vidas individuales, estructuras sociales y procesos históricos atendiendo la experiencia biográfica, no solo desde el campo de la sociología sino también desde otras consideraciones incluyendo análisis de tipo educativo. ${ }^{8}$

Otra corriente de interés dentro de los estudios biográficos se basa en las relaciones entre trayectorias de vida personales y el "curso de vida" de las instituciones. Los investigadores Ulrike Nagel y Fritz Schütze, de Otto-von-Guericke University of Magdeburg, reportan estudios en este campo. Aquí se halla, además, la aplicación de métodos biográficos para estudiar el desarrollo de identidades.

Entre las corrientes más específicas de investigación biográfica en educación sobresale la línea propuesta por Antonio Bolívar, Jesús Domingo y Manuel Fernández, académicos de la Universidad de Granada (España). Estos autores han venido desarrollando investigaciones que integran el componente narrativo a las dimensiones constitutivas de la experiencia de vida de los individuos. Entre sus principales ámbitos de investigación se encuentran: metodología de investigación del currículum, métodos biográficos en el desarrollo profesional y formación continua del profesorado, historia oral en historia de la educación, narrativas biográficas y fases en la vida profesional u organización como historia y narración (Bolívar et al., 2001: 217ss.).

Por su parte, en Open University, otros investigadores como Prue Chamberlayne, han explorado el uso de enfoques biográficos en entrenamiento profesional y evaluación. Dentro de los recursos biográficos en educación y entrenamiento, se destaca el uso de historias de vida como herramienta metodológica ordenada al análisis de la identidad profesional de educadores (motivos de elección de la carrera docente, giros vocacionales, prácticas laborales, etc.) o como posibilidad didáctica, por ejemplo, para el estudio de la historia. De esta manera, en la tendencia que aplica los estudios biográficos a cuestiones educativas se cuentan también recursos biográficos para desarrollar y analizar procesos de aprendizaje, cubiertos en la relación biografía-didáctica y biografía-formación. ${ }^{9}$

De particular interés resulta el "grupo de interés especial Biografía y educación" de la Escuela de Pedagogía de la Universidad de Southampton (Inglaterra). En la tradición instaurada por Michael Erben y su decisivo libro "Biografía y Educación", los investigadores Gill Clarke y Terry Martin, entienden el campo educativo en sentido amplio y

7 Según Kaźmierska, la sociología en Łódź fue influida por la reflexión intelectual sobre cultura e identidad nacional (concepto cultural de nación) en el marco de la sociología interpretativa. A mediados de los ochenta, el enfoque biográfico fue recuperado por los académicos de la cátedra de "Sociología de la Cultura" y se desarrolló gracias a la cooperación con Fritz Schütze.

8 De modo semejante a la IOHA, la Sociedad Internacional de Sociología dispone de un amplio elenco de consideraciones temáticas, entre las que se destacan: experiencias de exclusión, marginación y racismo; biografía y etnografía; desafíos metodológicos en la investigación biográfica; corporalidad; alimentación como símbolo cultural; migraciones transnacionales; biografía y experiencias con violencia; y la fundamentación de identidades profesionales en experiencias de vida.

9 Aquí se podrían inscribir algunas iniciativas de la historia de la educación que se han orientado a la escritura de reportes biográficos sobre personajes que desempeñaron un destacado papel educativo en la sociedad concreta que vivieron: Mary Bridges Adams, líder social en cuestiones de género en Australia o C. Patterson, consejero educativo. En el primer caso, el acento está puesto en los destacamentos socio-culturales; mientras en el segundo, en el recuento cronológico cercano a la biografía panorámica. 
no solo reducido al plano de la educación formal-escolar. De igual forma, se proponen ubicar el sentido de "lo biográfico" dentro de las directrices planteadas por las historias de vida, centrando su investigación en la naturaleza y el significado de vidas de individuos, o conjuntos de vidas entendidas dentro de su contexto social. Para ello usan estrategias de análisis narrativo y entienden la imaginación como recurso metodológico dentro de la investigación biográfica (aquí habría una acepción biográfica especial tendiente a la autoficción como estrategia narrativa para expresar el yo, problema de la relación biografía-literatura).

Desde aquí se ha conformado una importante Red que parte de los enfoques multidisciplinarios en investigación sobre historias de vida y que involucra centros británicos afines: el Centre for Life History and Life Writing Research (University of Sussex), el Centre for Lifelong Learning (Kent), el Center for International Studies of Diversity and Participation (Canterbury) y el Centre for Narrative Research (University of East London). Esta Red ha organizado el Congreso Internacional "Biografía y Educación" en Soupthampton, el cual permite una mirada plural a las narrativas escritas, habladas y visuales.

Otro grupo de investigaciones que expresan el acercamiento de la perspectiva biográfica a cuestiones educativas: es la línea de historias de vida para la formación de Gaston Pineau (Universidad de Tours) y el grupo de investigadores de la Universidad de Ginebra, como Jean Michel Baudouin y Pierre Dominicé. Las aplicaciones del enfoque biográfico a procesos de formación de adultos tienen, además, una presencia importante en Brasil en círculos de investigación de la Universidad de São Paulo y la Universidad del Estado de Bahía.

Por último, en cuarto lugar, se halla el enfoque que trabaja la biografía desde sus relaciones con la literatura y la narratividad, que remonta sus orígenes a una amplia tradición de tipologías biográficas tales como memorias, novelas, autobiografías, entre otros.

Desde Lytton Strachey con su biografía de la Reina Victoria hasta Oliver Todd con su "Albert Camus, una vida", la biografía moderna y, especialmente aquella de tradición francesa, es una particular tarea investigativa que convoca en un complejo dinamismo arte, expresión y ciencia. Como decía Barthes, toda biografía es una novela que no se atreve a decir su nombre. En verdad, hay ahí una formalización de la palabra, un trabajo del lenguaje, aunque no se trata de una producción de exclusivo dominio imaginario. La ficción adquiere, pues, un sentido de representación más que de irrealidad: la historia está "escrita" aún antes de ser texto. Así, la fuente de la literatura biográfica es la realidad humana misma, el curso de vidas y azares, de temores y esperanzas, de fantasmas y conquistas. Por citar sólo un ejemplo de una interminable lista, se podrá considerar la emblemática obra de Paul Auster titulada "La invención de la soledad" donde, con la sutileza de la literatura, se establecen densas reflexiones de familia, vínculos parentales, misterios de la memoria y de la muerte. ${ }^{10}$

Por su parte, los usos de la narratividad biográfica en educación están contribuyendo a los procesos existenciales e institucionales de creación continua del sujeto, como se aprecia en la línea trabajada por Jerome Bruner y los exponentes del enfoque experiencial

10 De gran pertinencia en este apartado resulta también el trabajo de Javier Marías, "Vidas escritas", que ofrece breves retratos literarios en torno a las existencias alternas, desconocidas e inusuales de hombres y mujeres de letras como William Faulkner, Joseph Conrad, Thomas Mann, Vladimir Nabokov, Madame Du Deffand, Vernon Lee, Rudyard Kipling y Oscar Wilde, entre otros. 
de la pedagogía (Jorge Larrosa, Carlos Skliar, Fernando Bárcena, entre otros). Uno de los presupuestos, como apunta Bruner, es que "el yo es un producto de nuestros relatos y no una cierta esencia por descubrir cavando en los confines de la subjetividad" (Bruner, 2003: 122). Al asumir la creación de la realidad desde la narración, que supone la sintonía entre identidad narrativa e identidad biográfica, se propicia una mediación interpretativa de la memoria y del tiempo a partir del relato que un individuo puede hacer de su vida experienciada. Esta interpretación de sí, acogida especialmente en los dispositivos de la autobiografía, está propiciando una revisión de la agenda teleológica de la escuela, de la acción cultural y de la profesión docente, que resignifique la pertinencia ética ante el drama de existir en medio de las múltiples complejidades del mundo actual.

\section{A MANERA DE CONCLUSIÓN: BIOGRAFÍA Y EDUCACIÓN, TRANSICIONES INACABADAS}

Para finalizar con algunos apuntes conclusivos, que en realidad son pautas para continuar la discusión, lo primero que debe tenerse en cuenta es la comprensión de "lo educativo" desde una perspectiva más amplia que la restringida a las acciones formales e institucionales de la enseñanza. Esta postura, como sugiere B. Roberts, permite examinar la relación entre biografía y pedagogía en términos del compromiso con el desarrollo de disposiciones reflexivas y ordenamientos éticos; es decir, cómo el sujeto se construye como tal en la simbiosis reflexión-acción, cómo se construyen y se re-crean las maneras de desenvolver la existencia en la escuela, la familia, la cultura, los escenarios de socialización, en general.

Ello supone, como bien ha intentado el enfoque experiencial de la pedagogía, establecer relaciones creativas, fundamentadas y razonables entre "la trayectoria vital del personaje con el contexto social en que lleva a cabo su actividad. Establecer en definitiva las conexiones entre los acontecimientos externos y la actividad pública que llenan de episodios la vida del individuo, con los procesos mentales y las vivencias íntimas que conforman su pensamiento y su específica manera de enfrentarse a la realidad circundante" (Carreras, 2005: 131).

Para emprender la tarea de análisis biográfico desde tal horizonte no debe desconocerse el desafío metodológico que supone la diversificación actual de fuentes para las "escrituras del yo" (autobiografías) o cualquier otra forma de memorias o representaciones de la existencia. Los llamados documentos visuales o documentos personales con mediación digital, al igual que la consideración de las artes como manifestaciones culturales de cierto sistema social (música, danzas, pintura e incluso alimentación) son textos emergentes de la praxis cotidiana de individuos y comunidades útiles a los estudios biográficos con fines educativos. Todo ello sin desmedro del avance brindado por la investigación biográfica en las ciencias sociales para el cultivo de las fuentes orales.

De igual forma, el asomo a territorios conceptuales de especial impacto en la organización de la historia contemporánea, alientan el constante desafío de legitimación del método. No sobra decir que un estudio biográfico moderno que pretenda contribuir en algo al debate, revisión y construcción de conocimientos de la pedagogía o de otro campo del saber, no podrá quedarse en una ejercitación solipsista o en una mirada endógena de la personalidad asumida como central para determinado estudio. Por el contrario, la 
escogencia de mecanismos biográficos para la investigación social y educativa funciona más como "detonante epistémico", es decir, como un lente que, con ciertos acentos, permite ver la realidad en sus múltiples vertientes y que comprende al individuo desde un presupuesto eminentemente relacional, para elaborar escalas de análisis que contribuyan a los procesos de teorización e intervención en el mundo de "lo real".

De ahí la importancia de abordar la comprensión biográfica desde un enfoque interpretativo, como bien han insistido las corrientes contemporáneas de la historia social que se han referido al tema. Desde aquí, la emergente biografía confronta el problemático paradigma historizante y se lanza a las tareas de reconstrucción de sentidos, significados, plataformas simbólicas, rituales y demás formas de estructuración que inciden en el curso de la vida humana, personal y colectiva.

En los cruces creativos de epistemologías, dispositivos, finalidades, tradiciones y alcances, se puede fijar hoy el horizonte de posibilidad biográfica junto a una reflexión pedagógica que, igualmente, confronta sus inveterados paradigmas y vigila las reducciones de sus márgenes de comprensión.

\section{REFERENCIAS BIBLIOGRÁFICAS}

Argüello, A. (2012). Entre el tiempo y el relato: Consideraciones epistemológicas en torno a la perspectiva biográfica en la investigación social y educativa. CPU-e, Revista de Investigación Educativa, $n$. 15, 27-47.

Bolívar, A., Domingo, J. y Fernández, M. (2001). La investigación biográfico-narrativa en educación. Enfoque y metodología. Madrid: La Muralla.

Birulés, F. (1996). Del sujeto a la subjetividad. Duro deseo de durar. En M. Cruz, (Ed.), Tiempo de subjetividad (pp. 223-234). Barcelona: Paidós,.

Bruner, J. (2003). La fábrica de historias. Derecho, literatura, vida. Buenos Aires: Fondo de Cultura Económica.

Castilla, A. y Fietta, J. (2009). Vivir las vidas ajenas. Babelia, Periódico El País No. 927, pp. 5-6.

Carreras, A. (2005). La biografía como objeto de investigación en el ámbito universitario. Reflexiones sobre un retorno. Asclepio, vol. LVII, n. 1, 125-133.

Corvez, M. (2000). Los estructuralistas. Buenos Aires: Amorrortu.

Denzin, N. (1989). Interpretative biography. Qualitative Research Methods. Newbury Park: Sage Publications, vol. 17.

Dosse, F. (2007). El arte de la biografía. Entre historia y ficción. México: UIA.

Duby, G. (1992). La historia continúa. Madrid: Debate.

Goodley, D. et al. (2004). Researching life stories. Method, theory and analysis in a biographical age. London: RoutledgeFalmer.

Mallimaci, F. y Giménez, V. (2006). Historia de vida y métodos biográficos. En Vasilachis, I. (Cord.), Estrategias de Investigación Cualitativa (pp. 175-212). Barcelona: Gedisa.

Plummer, K. (1989). La elaboración de un método. En Plummer, K., Los Documentos Personales (pp. 45-72) Madrid: Siglo XXI.

Sautu, R. (comp.) (2004). El método biográfico. La reconstrucción de la sociedad a partir del testimonio de los actores. Buenos Aires: Lumiere.

Solinger, R. et al. (2008). Telling stories to change the world: global voices on the power of narrative to build community and make social justice claims. New York: Routledge. 